\title{
O PERFIL DO CONSELHEIRO DE ADMINISTRAÇÃO E A LIDERANÇA ESTRATÉGICA
}

\author{
Ciro Antônio FERNANDES ${ }^{1}$ \\ Débora Sierra de GOUVEIA ${ }^{2}$ \\ Eduardo de Camargo OLIVA ${ }^{3}$ \\ Roberto Padilha MOÍA ${ }^{4}$
}

\begin{abstract}
${ }^{1}$ Doutorando em administração pela Universidade Municipal de São Caetano do Sul - USCS. Professor da Universidade Santa Cecília e Faculdade Don Domenico, Santos/São Paulo. ciro_af2@ @otmail.com.

${ }^{2}$ Mestranda em Administração pela Universidade Municipal de São Caetano do Sul. debora.sierra@uscs.edu.br.

${ }^{3}$ Pós Doutor em Administração pela FEA - USP. Professor e pesquisador do corpo permanente do Programa de Pós Graduação em Administração (mestrado e doutorado) da Universidade Municipal de São Caetano do Sul - USCS. eduardo.oliva@uscs.edu.br.
\end{abstract}

${ }^{4}$ Doutorando em administração pela Universidade Municipal de São Caetano do Sul. Coordenador do curso de marketing e professor do Centro Paula Souza, FATEC, em São Paulo. robertopadilha@uol.com.br.

Recebido em: 15/03/2015 - Aprovado em: 22/08/2016 - Disponibilizado em: 18/12/2016

\begin{abstract}
RESUMO:
O Conselho de Administração é uma obrigação para as grandes empresas no Brasil e no Mundo. Porém, muitos conflitos de interesses podem acontecer entre os conselheiros e os acionistas e dirigentes das empresas. Este estudo tem por objetivo analisar o perfil do conselheiro de administração no Brasil, levando em conta sua formação somada à sua experiência profissional, para que se possa conhecer se esses conselheiros possuem visão de líderes estratégicos. A amostra totaliza 240 empresas listadas nos níveis diferenciados de governança corporativa da BM\&F BOVESPA, e disponibilizados em websites das empresas. A pesquisa utiliza a técnica de análise multivariada de variáveis que exercem influência (variáveis independentes: $\mathrm{x}$ ) sobre outro fator (variável dependente: $\mathrm{y}$ ) é a de regressão. $\mathrm{O}$ resultado mostrou que as variáveis estatisticamente mais significantes foram número de experiências em outros conselhos, experiência em diretorias, experiência anterior como CEO e a constância que exerce a função de conselheiro. O resultado apontou para um perfil de liderança estratégica do Conselheiro de Administração, pelo menos nos limites dessa amostra.
\end{abstract}

Palavras-Chave: Perfil. Conselho de Administração. Conselheiro de Administração. Governança Corporativa.Liderança Estratégica.

\begin{abstract}
:
The Board of Directors is a must for large companies in Brazil and the world. But many conflicts of interest can occur between the directors and the shareholders and directors of companies. This study aims to analyze the board member's profile in Brazil, taking into account their education added to his professional experience, so that you can know if these advisers have vision of strategic leaders. The sample totaled 240 companies listed in different levels of corporate governance of BM \& F BOVESPA, and made available on company websites. The research uses the multivariate analysis technique variables that influence (independent variables: $\mathrm{x}$ ) on another factor (dependent variable $\mathrm{y}$ ) is the regression. The result showed that the most statistically significant variables were number of experiences in other councils, boards experience, previous experience as CEO and constancy holding the adviser. The results pointed to a strategic leadership profile Board member, at least within the limits of the sample.
\end{abstract}

Keywords: Profile. Administrative Board. Board Member. Corporate Governance. Strategic Leadership. 


\section{INTRODUÇÃO}

A adoção do conselho de administração pelas empresas tem sido algo muito estudado (ANDRES; VALLELADO, 2008; GONDRIGE, 2012; ACEITUNO, 2013; HOLTZ, 2014; STEVENSON; RADIN, 2015), principalmente no sentido de se buscar melhoriasnas relações das empresas com seus investidores, na tomada de decisões, transparência e credibilidade, ações estas que fazem parte das melhores práticas de governança corporativa (ROSSONI, 2010). Dentro desse contexto, vê-se a necessidadede conselheirosde administração com competências estratégicas, capazes de atuar diretamente na resolução de problemas e na tomada de decisões. (MARTINS, etal, 2012).Na definição de um perfil de conselheiro de administração com visão mais estratégica, a literatura sugere a escolha de líderes que utilizem a visão da liderança estratégica (MOSTOVICZ et al, 2009; NASTASE, 2010; HITT et al, 2012; SIMSEK et al, 2015). Por meio dela, a conduta do conselheiro se torna uma referência para pessoas de dentro e de fora da organização, pois esse perfil de liderança empenha seu entusiasmo e confiança pessoal para que possa implementar as ações necessárias que garantam o cumprimento dos objetivos estratégicos (NASTASE, 2010). Porém, o que tem ocorrido é a constituição de conselhos com pessoas que não conseguem atuar com uma visão estratégica, muitas vezes, em função de uma formação não condizente, ou porque, sua formação é muito limitada, ou, tem pouca experiência como conselheiro de administração (NASTASE, 2010). A questão de uma formação acadêmica em associada a experiência profissional, pode ser uma das hipóteses que valida que o conselheiro de administração tem uma visão de liderança estratégica (MOSTOVICZ et al, 2009; MARTINS et al, 2012). Esta pesquisa objetiva analisar o perfil do conselheiro de administração no Brasil, levando em conta sua formação somada à sua experiência profissional, para que se possa conhecer se esses conselheiros possuem visão de líderes estratégicos. Assim, através da análise curricular dos conselheiros que fazem parte do Conselho de Administração das empresas listadas nos níveis diferenciados degovernança corporativa da $\mathrm{BM} \& \mathrm{~F}$ BOVESPA, e disponibilizados em websites das empresas, pretende-se investiga a relação entre os elementos que compõem sua formação, com vistas à responder a seguinte questão de pesquisa: a formação e a experiência dos Conselheiros de Administração apontam para uma visão de liderança estratégica?

\section{GOVERNANÇA CORPORATIVA}

Os estudos sobre governança corporativa se intensificaram a partir dos anos oitenta, sendo que atualmente domina as discussões nas mais diversas áreas, como, 
direito, contabilidade, economia e finanças, envolvendo discussões e estudos nos ambientes acadêmicos e empresariais (ALMEIDA, 2010).

Segundo IBGC (2015, p. 21), Governança Corporativa é o meio pelo qual as "as organizações são dirigidas, monitoradas e incentivadas, envolvendo os relacionamentos entre sócios, conselho de administração, diretoria, órgãos de fiscalização e controle e demais partes interessadas".

As boas práticas de Governança Corporativa permite alinhar os interesses dos acionistas aos da organização, preserva e aumenta o valor acionário dentro do mercado de capitais e atrai novosinvestidores, o que contribui para a longevidade do negócio.Para que as boas práticas de governança sejam efetivamente executadas, cabe ao conselho de administração monitorar as ações e decisões da diretoria da empresa (OLIVEIRA et al, 2013). Nesse sentido,o conselho de administração precisa reunir conselheiros com competências, incluindo a liderança estratégica, que auxilia no desenvolvimento do papel de conselho (AMARAL-BAPTISTA et al, 2012).

\section{LIDERANÇA ESTRATÉGICA}

A teoria da liderança estratégica tem se tornado atraente, pois auxilia no aumento do número e na qualidade dos líderes em vários setores (NASTASE, 2010). Os líderes estratégicos precisam levar em consideração o dinamismo ambiental para que possam atuar de maneira eficaz na conduta de suas atribuições (JANSEN, et. al, 2009). Nesse sentido, a liderança focada nos objetivos a serem alcançados exige do líder um compromisso total e permanente. Os líderes precisam se preocupar menos com o que fizeram e se comprometer mais com os propósitos futuros (MOSTOVICZ et al, 2009). Com essa visão de futuro, a liderança estratégica busca integrar e organizar os ambientes internos e externos das empresas, para que possa desenvolver negócios a partir do gerenciamento das informações e participando ativamente de todas as etapas (JOOSTE \& FOURIE, 2009). A diferença dos líderes pode estar no Know-How, termo que pode ser definido como um conjunto de conhecimentos práticos adquiridos por um indivíduo, constituindo, uma característica valiosa resultante da experiência. (CHARAN, 2007). Ainda, segundo o autor, o Know-How do líder será constantemente testado, uma vez que ele deve tomar as decisões corretas e produzir resultados que criem valor ao negócio. Segundo Mintzberg (2010, p. 150) os líderes "desenvolvem suas estruturas de conhecimento e seus processos de pensamento, principalmente por meio de experiência direta. Essa experiência dá forma àquilo que eles sabem, o que por sua vez dá forma ao que eles fazem, moldando sua experiência subseqüente". 


\section{ASPECTOS METODOLÓGICOS}

Para que o objetivo desta pesquisa fosse alcançado, foram analisados fatores que identificassem o perfil do conselheiro de administração. Para isso foram consideradosinicialmente a formação acadêmica e experiência profissional dos conselheiros de administração. Posteriormente, as variáveis encontradas foram analisadas com o objetivo de encontrar ou não trações de liderança estratégica no perfil dos conselheiros de administração. Foram realizados testes a partir do programa Statistical Package for the Social Sciences (SPSS), com amostra de 240 currículos de conselheiros de administração, obtidosem sites de empresas de capital aberto, listadas nos níveis diferenciados de governança corporativa da BM\&F BOVESPA. A técnica estatística que permite uma análise multivariada de variáveis que exercem influência (variáveis independentes: $x$ ) sobre outro fator (variável dependente: y) é a de regressão. A variável dependente yrefere-se a presença ou não da característica "conselheiro de administração" (variáveis dummy $=1$ presença da característica "conselheiro de administração"; 0 = ausência da característica “conselheiro de administração").

Como as informações contidas nesta variável - conforme Quadro 1 - são de natureza qualitativa, optou-se pelo uso da regressão logística binária.
Quadro 1 - Variáveis Disponíveis para Testes e sua Natureza

\begin{tabular}{|c|c|}
\hline $\begin{array}{c}\text { Variáveis totais disponíveis } \\
\text { para testes }\end{array}$ & $\begin{array}{c}\text { Natureza dos } \\
\text { dados }\end{array}$ \\
\hline Sexo & Nominal \\
\hline Graduação 1 & Nominal \\
\hline Graduação 2 & Nominal \\
\hline Graduação 3 & Nominal \\
\hline Especialização 1 & Nominal \\
\hline Especialização 2 & Nominal \\
\hline Especialização 3 & Nominal \\
\hline Especialização 4 & Nominal \\
\hline Mestrado 1 & Nominal \\
\hline Mestrado 2 & Nominal \\
\hline Doutorado & Nominal \\
\hline $\mathrm{PhD}$ & Nominal \\
\hline Pós Doutorado & Nominal \\
\hline Outras Certificações & Razão \\
\hline Experiência Profissional & Nominal \\
\hline n Experiência Diretoria & Razão \\
\hline n Experiência Gerência & Razão \\
\hline n Experiência Cargos Políticos & Razão \\
\hline $\begin{array}{l}\text { n Experiência de Participação } \\
\text { em Outros Conselhos }\end{array}$ & Razão \\
\hline $\begin{array}{l}\text { n Experiência de Participação } \\
\text { em Comitês }\end{array}$ & Razão \\
\hline Cargos Que Ocupou & Nominal \\
\hline
\end{tabular}

Fonte: Criado pelos autores.

$\mathrm{Na}$ variável Graduação (nome do curso)contêm 23 cursos diferentes. A variável Graduação 2, que apresenta o nome do curso da segunda graduação pode ser considerada como outlier, uma vez que dos 240 indivíduos, somente 23 a possuíam. Para as demais variáveis nominais, o mesmo raciocínio e precaução existiram na análise prévia do banco de dados. Em decorrência do tamanho limitado da amostra e da possível presença de outlier - após todos os ajustes, o banco de dados passou a ter 187 indivíduos, foram escolhidas as variáveis consideradas comuns, isto é, as variáveis que os indivíduos 
em sua massiva maioria compartilhavam, conforme demonstra o

Quadro 2.

Quadro 2 - Variáveis Mantidas e sua Natureza

\begin{tabular}{|c|c|}
\hline Variáveis mantidas & $\begin{array}{c}\text { Natureza dos } \\
\text { dados }\end{array}$ \\
\hline Sexo & Nominal \\
\hline Grande Área da Primeira Formação & Nominal \\
\hline $\begin{array}{l}\text { Sócio, Fundador ou Proprietário em } \\
\text { Organizaçóes }\end{array}$ & Nominal \\
\hline $\begin{array}{l}\text { Experiência Anterior como Presidente } \\
\text { ou Vice no CA }\end{array}$ & Nominal \\
\hline Experiência Anterior como CEO & Nominal \\
\hline $\begin{array}{l}\text { Experiência Anterior como Vice- } \\
\text { presidente }\end{array}$ & Nominal \\
\hline n Títulos e Certificações & Razão \\
\hline n Experiência Diretoria & Razão \\
\hline n Experiência Gerência & Razão \\
\hline n Experiência Cargos Políticos & Razão \\
\hline $\begin{array}{l}\text { n Experiência de Participação em } \\
\text { Outros Conselhos }\end{array}$ & Razão \\
\hline $\begin{array}{l}\text { n Experiência de Participação em } \\
\text { Comitês }\end{array}$ & Razão \\
\hline
\end{tabular}

Fonte: Criado pelos autores.

A variável Graduação ao invés de apresentar o nome do curso, passou a apresentar a grande área que pertencia, por exemplo, todas as modalidades do curso de Engenharia, como civil, elétrica, de produção, e etc. A variável "Outras Certificações", apresenta o número de certificações do indivíduo e os títulos que possuem (Títulos considerados: especialização, mestrado, doutorado, $\mathrm{PhD}$ e pós-doutorado). A variável Experiência foi desdobrada em nove. Cinco variáveispassaram a apresentar o número de experiências anteriores e quatro passaram a informar existência da antiga experiência ou não do indivíduo em cargos como $\mathrm{CEO}$, vicepresidente de outras organizações, vicepresidente ou presidente em outros conselhos de administração e experiência como sócio, fundador ou proprietário em outras organizações, conforme apresenta o

Quadro 3.

Quadro 3 - Variáveis para o Modelo

\begin{tabular}{|c|c|c|}
\hline $\begin{array}{l}\text { Tipo de } \\
\text { Variável }\end{array}$ & $\begin{array}{l}\text { Variáveis } \\
\text { testadas }\end{array}$ & $\begin{array}{l}\text { Opções de } \\
\text { Respostas }\end{array}$ \\
\hline y dependete & $\begin{array}{l}\text { Conselheiro } \\
\text { de } \\
\text { Administração }\end{array}$ & $\begin{array}{lr}\text { 1: Conselheiro de } \\
\text { Administração } \\
0: \quad \text { Não } \\
\text { Conselheiro é } \\
\text { Administração }\end{array}$ \\
\hline $\mathrm{x}$ independente & Sexo & $\begin{array}{l}\text { Feminino } \\
\text { Masculino }\end{array}$ \\
\hline $\mathrm{x}$ independente & $\begin{array}{l}\text { Grande Área } \\
\text { da Primeira } \\
\text { Formação }\end{array}$ & $\begin{array}{l}\text { Administração } \\
\text { Engenharia } \\
\text { Direito }\end{array}$ \\
\hline $\mathrm{x}$ independente & $\begin{array}{l}\text { Sócio, } \\
\text { Fundador ou } \\
\text { Proprietário } \\
\text { em } \\
\text { Organizações }\end{array}$ & $\begin{array}{l}\text { 1: Sócio, Fundador } \\
\text { ou Proprietário em } \\
\text { Organizações } \\
\text { 0: Nunca foi Sócio, } \\
\text { Fundador } \\
\text { Proprietário eu } \\
\text { Organizações }\end{array}$ \\
\hline $\mathrm{x}$ independente & $\begin{array}{l}\text { Experiência } \\
\text { Anterior como } \\
\text { Presidente ou } \\
\text { Vice no CA }\end{array}$ & $\begin{array}{l}\text { experiência } \\
\text { 0: Não possui a } \\
\text { experiência. }\end{array}$ \\
\hline $\mathrm{x}$ independente & $\begin{array}{l}\text { Experiência } \\
\text { Anterior como } \\
\text { Ceo }\end{array}$ & $\begin{array}{l}\text { 1: Possui a } \\
\text { experiência } \\
0: \text { Não possui a } \\
\text { experiência. }\end{array}$ \\
\hline $\mathrm{x}$ independente & $\begin{array}{l}\text { Experiência } \\
\text { Anterior como } \\
\text { Vice-Presiente } \\
\text {.................... }\end{array}$ & $\begin{array}{l}\text { 1: Possui a } \\
\text { experiência } \\
0: \text { Não possui a } \\
\text { experiência. }\end{array}$ \\
\hline $\mathrm{x}$ independente & $\begin{array}{l}\text { n Títulos } \\
\text { eCertificações }\end{array}$ & Número Razão \\
\hline $\mathrm{x}$ independente & $\begin{array}{l}\text { n Experiência } \\
\text { Diretoria }\end{array}$ & Número Razão \\
\hline $\mathrm{x}$ independente & $\begin{array}{l}\text { n Experiência } \\
\text { Gerência }\end{array}$ & Número Razão \\
\hline $\mathrm{x}$ independente & $\begin{array}{l}\text { n Experiência } \\
\text { Cargos }\end{array}$ & Número Razão \\
\hline $\mathrm{x}$ independente & $\begin{array}{l}\text { n Experiência } \\
\text { de } \\
\text { Participação } \\
\text { em Outros } \\
\text { Conselhos }\end{array}$ & Número Razão \\
\hline $\mathrm{x}$ independente & $\begin{array}{l}\text { n Experiência } \\
\text { de } \\
\text { Participação } \\
\text { em Comitês }\end{array}$ & Número Razão \\
\hline
\end{tabular}


Fonte: Criado pelos autores.

\section{RESULTADOS}

$\mathrm{Na}$ criação do modelo de regressão foram realizados dois tipos de testes para a verificação da dependência entre as variáveis $x$ ey: os testes do Qui-Quadrado e o do MannWhitney. Para ambos os testes, rejeita-se a hipótese nula, para que a estatística evidencie que existem diferenças significativas entre os grupos de onde foram extraídas as amostras. (MAROCO, 2003). Na hipótese H0, não existem diferenças entre as amostras relativas à distribuição nas classes da variável; ou a distribuição das contagens pelos grupos é independente da variável. Na hipótese H1 existem diferenças significativas entre os grupos ou populações onde foram extraídas as amostras.Para as variáveis nominais foi utilizado o Teste do Qui-Quadrado, tabela 1.

Tabela 1- Teste do Qui-Quadrado

\begin{tabular}{|c|c|c|}
\hline Variável & p-valor & Interpretação \\
\hline Sexo & 0,37 & $\begin{array}{c}\text { Não se pode rejeitar } \\
\text { a H0.* }\end{array}$ \\
\hline $\begin{array}{c}\text { Grande Área da } \\
\text { Primeira Formação }\end{array}$ & 0,94 & $\begin{array}{c}\text { Não se pode rejeitar } \\
\text { a H0. }\end{array}$ \\
\hline $\begin{array}{c}\text { Sócio, Fundador ou } \\
\text { Proprietário em } \\
\text { Organizações }\end{array}$ & 0,40 & $\begin{array}{c}\text { Não se pode rejeitar } \\
\text { a H0. }\end{array}$ \\
\hline $\begin{array}{c}\text { Experiência } \\
\text { Anterior como } \\
\text { Presidente ou Vice } \\
\text { no CA }\end{array}$ & 0,05 & Rejeita-se a H0. \\
\hline $\begin{array}{c}\text { Experiência } \\
\text { Anterior como CEO }\end{array}$ & 0,00 & Rejeita-se a H0. \\
\hline $\begin{array}{c}\text { Experiência } \\
\text { Anterior como } \\
\text { Vice-presidente }\end{array}$ & 0,10 & $\begin{array}{c}\text { Não se pode rejeitar } \\
\text { a H0. }\end{array}$ \\
\hline
\end{tabular}

Fonte: Criado pelos autores.

*1 cells $(25 \%)$ have expected count less than 5 . The minimum expected count is 4 .
Esta informação já era esperada devido ao perfil da amostra que possui um número de indivíduos do sexo feminino bem inferior ao número de indivíduos do sexo masculino. Desta forma, o teste será considerado. Para as variáveis numéricas (n títulos e certificações, $\mathrm{n}$ experiência diretoria, n experiência gerência, $n$ experiência cargos políticos, $\mathrm{n}$ experiência de participação em outros conselhos, $\mathrm{n}$ experiência de participação em comitês) foi utilizado o teste de Mann-Whitney, tabela 2.

Tabela 2- Teste de Mann-Whitney

\begin{tabular}{c|c|c}
\hline Variável & p-valor & Interpretação \\
\hline n Títulos e Certificações & 0,427 & $\begin{array}{c}\text { Não se pode } \\
\text { rejeitar a H0. }\end{array}$ \\
\hline n Experiência Diretoria & 0,004 & Rejeita-se a H0. \\
\hline n Experiência Gerência & 0,480 & $\begin{array}{c}\text { Não se pode } \\
\text { rejeitar a H0. }\end{array}$ \\
\hline $\begin{array}{c}\text { n Experiência Cargos } \\
\text { Políticos }\end{array}$ & 0,544 & $\begin{array}{c}\text { Não se pode } \\
\text { rejeitar a H0. }\end{array}$ \\
\hline $\begin{array}{c}\text { n Experiência de } \\
\text { Participação em Outros } \\
\text { Conselhos }\end{array}$ & 0,001 & Rejeita-se a H0. \\
\hline $\begin{array}{c}\text { n Experiência de } \\
\text { Participação em } \\
\text { Comitês }\end{array}$ & 0,006 & Rejeita-se a H0. \\
\hline
\end{tabular}

Fonte: Criado pelos autores.

Após a realização destes testes foi possível encontrar as variáveis independentes relacionadas com a variável independente, para então o início das análises da regressão.

As variáveisque permanecerão no modelo, conforme a

Quadro, são:

Quadro 4 - Variáveis x relacionadas com a variável y

Número de experiências em outros conselhos

Número de experiências em comitês

Número de experiências em diretoria 
\begin{tabular}{|l|} 
Experiência anterior como CEO \\
\hline Experiência anterior como Vice-Conselheiro \\
\hline
\end{tabular}

Fonte: Criado pelos autores.

Para que o modelo de estimação da regressão logística binária fosse definido, foram realizadas análises para a verificação da existência da multicolinearidade através da estimação de uma regressão linear. Para admitir a existência ou não de multicolinearidade nos parâmetros determinados, as análises serão concluídas em três etapas:

I - Análise do $\mathrm{R}^{2}$ e suas estatísticas $\mathrm{T}$ : Das seis variáveis existentes no modelo, apenas duas são estatisticamente significantes (considerando 5\% de significância). Contudo, o coeficiente de determinação do modelo ( $\mathrm{R}$ Square) está médio, não indicando a presença de multicolinearidade.

II - As correlações entre as variáveis tomadas duas a duas estão todas abaixo de 0,325. Esta estatística evidencia o que duas variáveis compartilham em sua explicação. Uma estatística de $32,5 \%$ é considerada como uma baixa autocorrelação, não indicando a presença da multicolinearidade.

III - Para a verificação da presença da multicolinearidadefoi realizada a análise do Value Inflation Factor - VIF, em que as estatísticas precisam estar apresentando um valor de até 5 , segundo os autores Gujarati e Porter (2011).

Conforme verificado a estatística não indica a existência de multicolinearidade, visto que seus valores estão abaixo de 1,2. Conforme as análises, não há a indicação da presença de multicolinearidade, direcionando assim nosso método de estimação da regressão logística binária para Enter, o qual permite que todas as variáveis estejam,em uma única vez, inseridas no modelo (ao contráriodo método de estimação Forward Conditional, que insere automaticamente as variáveis a cada interação e individualmente).Segundo a estatística $\operatorname{Exp}(B)$ a variável mais importante desta regressão é a Experiência Anterior como $\mathrm{CEO}$, seguida pelo $\mathrm{n}$ de Experiências em Cargos de Diretoria, número de Experiência em Outros Conselhos, número de Experiências em Comitês e Experiência Anterior Como Vice-Presidente.Verificou-se que somente as variáveis Número de Experiências em Comitês e Experiência anterior como Vice Conselheiro, não são estatisticamente significantes, por rejeitarem a H0, pois p-valor da estatística Wald é menor do que 5\%. Todas as demais variáveis estudadas e inclusas neste modelo mostraramse como estatisticamente significantes, como demonstrado no quadro 5. 
Quadro 5 - Variáveis estatisticamente significantes

\begin{tabular}{|c|c|c|}
\hline $\begin{array}{c}\text { Variáveis } \\
\text { estatisticamente } \\
\text { significantes } \\
\end{array}$ & valor & Interpretação \\
\hline $\begin{array}{lr}\text { Número } & \mathrm{de} \\
\text { experiências } & \mathrm{em} \\
\text { comitês } & \end{array}$ & 0,167 & $\begin{array}{l}\text { Aceitação da H0, ou seja, não } \\
\text { há evidências de que o } \\
\text { parâmetro é estatisticamente } \\
\text { significante }\end{array}$ \\
\hline $\begin{array}{l}\text { Experiência } \\
\text { anterior como } \\
\text { Vice- } \\
\text { Conselheiro } \\
\end{array}$ & 0,419 & $\begin{array}{l}\text { Aceitação da H0, ou seja, não } \\
\text { há evidências de que o } \\
\text { parâmetro é estatisticamente } \\
\text { significante }\end{array}$ \\
\hline $\begin{array}{l}\text { Número de } \\
\text { experiências em } \\
\text { outros conselhos }\end{array}$ & 0,034 & $\begin{array}{l}\text { Rejeição da } \mathrm{H} 0 \text {, ou seja, há } \\
\text { evidências de que o } \\
\text { parâmetro é estatisticamente } \\
\text { significante }\end{array}$ \\
\hline $\begin{array}{lr}\text { Número } & \text { de } \\
\text { experiências } & \text { em } \\
\text { diretoria } & \end{array}$ & 0,004 & $\begin{array}{l}\text { Rejeição da } \mathrm{H} 0 \text {, ou seja, há } \\
\text { evidências de que o } \\
\text { parâmetro é estatisticamente } \\
\text { significante }\end{array}$ \\
\hline $\begin{array}{l}\text { Experiência } \\
\text { anterior como } \\
\mathrm{CEO}\end{array}$ & 0,000 & $\begin{array}{l}\text { Rejeição da } \mathrm{H} 0 \text {, ou seja, há } \\
\text { evidências de que o } \\
\text { parâmetro é estatisticamente } \\
\text { significante }\end{array}$ \\
\hline Constante & ,02 & $\begin{array}{l}\text { Rejeição da } \mathrm{H} 0 \text {, ou } \\
\text { seja, há evidências de que o } \\
\text { parâmetro é estatisticamente } \\
\text { significante }\end{array}$ \\
\hline
\end{tabular}

Fonte: Os autores

O teste de Omnibus apresenta o ajuste geral do modelo através da análise da verossimilhança (-2LL). Com a significância de $0,00 \%$ (sig. $<5 \%$ ), foi rejeitada a hipótese nula de que a não houve variação da máxima verossimilhança, indicando que os coeficientes inclusos no modelo são estatisticamente significantes sendo então adequadas para a realização de previsões (HAIR et al, 2009).O teste de Hosmer e Lemeshow apresenta uma hipótese nula de que a classificação do modelo é igual à original. A intenção é de não se rejeitar a hipótese nula, ou seja, a correspondência dos valores reais e os previstos sobre a variável dependente possuem o melhor ajuste do modelo e é dado pela menor diferença entre classificação observada e a prevista. $\mathrm{A} H_{0}$ não pode ser rejeitada com a significância de 0,621 , indicando que os valores estimados não são apresentam uma diferença significativa dos valores observados.Através da Tabela de Classificação é possível analisar quanto um modelo é apropriado em comparação com os dados reais. O modelo estimado possui melhor capacidade de classificar indivíduos que são conselheiros de administração, considerando o percentual acertado de $85,7 \%$ ser maior do que o percentual geral de $71,1 \%$. Contudo, para que seja considerado que o modelo possui capacidade preditiva, o percentual geral deveria ser $25 \%$ maior do que todos os casos de indivíduos conselheiros de administração apresentados (119 casos). Ou seja, o modelo deveria apresentar 79,54\% de acerto, quando o valor efetivo apresentado foi de $71,1 \%$, indicando que o modelo possui baixa capacidade preditiva (HAIR, 2009). A estatística Pseudo $\mathrm{R}^{2}$ é uma medida de adequação de ajuste e medem a correspondência entre os valores observados e os valores previstos da variável dependente, sendo que os valores mais altos significam um melhor ajuste do modelo das probabilidades estimadas com as probabilidades observadas (HAIR, 2009). Neste estudo, o modelo apresentou um baixo poder de explicação: 17,81\%. Analisando os resultados da Tabela de Classificação e do Pseudo $\mathrm{R}^{2}$, pode-se afirmar que há mais variáveis que precisam 
ser exploradas e testadas para ser incorporadas ao modelo.

\section{CONCLUSÕES}

Esta pesquisa objetivou analisar o perfil do conselheiro de administração no Brasil, levando em conta a formação acadêmicae experiência profissional, para que se verificara existência doperfil de líderes estratégicos nos conselheiros de administração. Os resultados apontaram para uma formação mínima superior em todos os casos. Na variável experiência profissional é possível validarmos que a experiência evidencia um dos principais atributos do conselheiro de administração.Tais resultados sugerem que o conselheiro de administração, no Brasil,possuium perfil de liderança

\section{REFERÊNCIAS}

ACEITUNO, J. V. F.; RODRIGUEZ-ARIZA, L.; GARCIA-SANCHEZ, I. M. The role of the board in the dissemination of integrated corporate social reporting. Corporate Social Responsibility and Environmental Management, v. 20, n. 4, p. 219-233, 2013.

ALMEIDA, M. A. Evolução da qualidade das práticas de governança corporativa: um estudo das empresas brasileiras de capital aberto não listadas em bolsa. Revista de Administração Contemporânea, v. 14, n. 5, p. 907-924, 2010.

AMARAL-BAPTISTA, M.; MELO, M. A.; MACEDO-SOARES, T. D. Conselhos de administração e monitoração daimplementação estratégica: um modelo conceitual. Economia Global e Gestão, v. 17, n. ESPECIAL, p. 55-75, 2012. estratégica. Nesse caso, sugere-se que para escolha dos conselheiros de administração, as empresas levem em consideração essas duas variáveis, podendo assim, ter uma probabilidade maior de assertividade na escolha dos conselheiros com perfil de líder estratégico.Uma das limitações da pesquisa é a faltade informações que não refletem,de maneira mais detalhada, o currículo atual dos conselheiros, para uma avaliação mais depurada de seus perfis. Nesse sentido, sugere-se para novos estudos maior profundidade, associada a entrevistas para coletar e analisar as características ou traços de liderança estratégica, e assim complementar e validar essa pesquisa.

ANDRES, P.; VALLELADO, E. Corporate governance in banking: The role of the board of directors. Journal of banking \& finance, v. 32, n. 12, p. 2570-2580, 2008.

CHARAN, R. Know-How. As 8 competências que separam os que fazem dos que não fazem. Rio de Janeiro: Elsevier, 2007.

GONDRIGE, E. O.; CLEMENTE, A.; ESPEJO, M. M. S. B. Estrutura do conselho de administração e valor das companhias brasileiras. BBR-Brazilian Business Review, v. 9, n. 3, p. 72-95, 2012.

GUJARATI, D. N. Basic econometrics. Tata McGraw-Hill Education, 2009.

HAIR, J. F. et al. Análise multivariada de dados . Bookman Editora, 2009. 
HITT, M. A.; HAYNES, K. T.; SERPA, R. Strategic leadership for the $21 \mathrm{st}$ century. Business Horizons, v. 53, p. 437444, 2010.

HOLTZ, L.; ALMEIDA, J. E. F. Estudo sobre a Relevância e a Divulgação dos Ativos Biológicos das Empresas Listadas na BM\&FBOVESPA. Sociedade, Contabilidade e Gestão, v. 8, n. 2, 2013.

INSTITUTO BRASILEIRO DE GOVERNANÇA CORPORATIVA - IBGC. Código das melhores práticas de governança corporativa. 5.ed. / Instituto Brasileiro de Governança Corporativa. São Paulo, SP: IBGC, 2015.

JANSEN, J.; VERA, D.; CROSSAN, M. Strategic leadership for exploration and exploitation: The moderating role of environmental dynamism. The Leadership Quarterly, v. 20, n. 1, p. 5-18, 2009.

JOOSTE, C.; FOURIE, B. The role of strategic leadership in effective strategy implementation: Perceptions of South African strategic leaders.Southern African Business Review, v. 13, n. 3, p. 51-68, 2009.

MAROCO, J. Análise Estatística. Sílabo Editora, 2003.

MARTINS, O. S.et al. Características e competências dos conselhos de administração de bancos brasileiros e suas relações com seus desempenhos financeiros. Revista Universo Contábil, v. 8, n. 3, p. 40-61, 2012.

MINTZBERG, H; AHLSTRAND, B; LAMPEL, J. Safári de estratégias: um roteiro pela selva do planejamento estratégico. ed. 2. Porto Alegre: Bookman, 2010.

MOSTOVICZ, E.;KAKABADSE, N.; KAKABADSE, A. P.A dynamic theory of leadership development. Leadership \&Organization Development Journal, v. 30, n. 6, p. 563-576, 2009.
OLIVEIRA, M. C. et al. Práticas de governança corporativa adotadas por companhias fechadas brasileiras e alinhamento às demandas do mercado de capitais. BASE-Revista de Administração e Contabilidade da UNISINOS, v. 10, n. 3, p. 196-209, 2013.

ROSSONI, L.; MACHADO-DA-SILVA, C. L. Organizational institutionalism and corporate governance. Revista de Administração Contemporânea, v. 14, n. SPE, p. 173-198, 2010.

SIMSEK, Z.et al. Strategic leadership and leaders in entrepreneurial contexts: A nexus for innovation and impact missed?. Journal of Management Studies, v. 52, n. 4, p. 463478, 2015.

STEVENSON, W. B.; RADIN, R. F. The minds of the board of directors: the effects of formal position and informal networks among board members on influence and decision making. Journal of Management \&Governance, v. 19, n. 2, p. 421-460, 2015. 